\title{
Experimental generation of tsunami-like waves
}

\author{
D. Wüthrich ${ }^{1}$, I. Nistor ${ }^{2}$, M. Pfister ${ }^{3}$ and A. J. Schleiss ${ }^{4}$ \\ ${ }^{1}$ Laboratory of Hydraulic Constructions (LCH), Ecole Polytechnique Fédérale de \\ Lausanne (EPFL), CH-1015 Lausanne, Switzerland. Email: davide.wuthrich@epfl.ch \\ ${ }^{2}$ Dep. of Civil Engineering, Univ. of Ottawa, 161 Louis-Pasteur, Ottawa, ON, \\ Canada K1N 6N5. E-mail: inistor@uottawa.ca \\ ${ }^{3}$ Laboratory of Hydraulic Constructions (LCH), Ecole Polytechnique Fédérale de \\ Lausanne (EPFL), CH-1015 Lausanne, Switzerland. Email: michael.pfister@epfl.ch \\ ${ }^{4}$ Laboratory of Hydraulic Constructions (LCH), Ecole Polytechnique Fédérale de \\ Lausanne (EPFL), CH-1015 Lausanne, Switzerland. Email: anton.schleiss@epfl.ch
}

\begin{abstract}
In the context of a comprehensive research project investigating the hydrodynamic loading on structures with openings, this paper focuses on the wave generation techniques currently used and the test results associated with it, proposing a particular tsunami-like wave using a vertical water volume release mechanism. The latter allowed a certain volume of water to flow gravitationally from an upper reservoir into a lower basin through a set of pipes. The propagation of the resulting wave took place in a horizontal channel where wave height and velocities were measured. Both dry bed surges and wet bed bores were investigated, however the present paper mostly focuses on dry bed surges. The study indicated that the surges generated with this mechanism had similar behavior to those resulting from a DamBreak technique and a good agreement between the experimental points and the theoretical solutions of Ritter (1892) and Whitham (1955) was found. Lastly some differences between wet bed bores and dry bed surges are presented and briefly discussed herein.
\end{abstract}

\section{INTRODUCTION AND RESEARCH NEEDS}

Impacts of extreme wave-induced bores on structures used to be considered rare events and hydrodynamic loading on near-shore structures was typically neglected in the design process. Impulse waves and tsunamis often generate coastal/near-shore flooding which can induce extreme damage to infrastructure and loss of human lives. Chanson (2006) demonstrated the strong similarity between dam-break waves and the hydraulic bores generated by broken tsunami waves advancing inland. Recent catastrophic events such as the 2004 Indian Ocean Tsunami and the 2011 Tohoku Japan Tsunami showed that engineering and coastal planning measures must be considered to ensure people's safety and reduce reconstruction costs in coastal areas. Some previous studies on the impact of waves against structures were carried out by various researchers to characterise and estimate this extreme hydrodynamic loading. However, the large amount of empirical or semi- 
empirical formulas proposed and the significant scattering of their results indicate that the complex behaviour of structures under such extreme loading is not yet fully understood. Post-tsunami field observations and surveys showed that buildings with openings seem to resist better under hydrodynamic impact (Chock et al. 2012).

The purpose of this research project conducted at LCH-EPFL, Switzerland, focuses on investigating the effect of openings on the resulting base shear force through a systematic experimental work, however this article focuses on the wave generation technique and propagation along the channel. After a brief introduction on the main existing techniques to produce wave, an implementation of the vertical release technique is further discussed. Particular emphasis is given to the surges on dry bed and a comparison with the theoretical solutions of Ritter (1892) and Whitham (1955) is presented. In the last section, dry bed surges are compared to wet bed bores and main differences discussed.

\section{WAVE GENERATION TECHNIQUES}

Many techniques can be used to produce waves depending on the phenomenon to be investigated. Four main categories can be listed:

1. Wave Pistons - Waves are produced mechanically through the horizontal movement of a paddle. This technique produces mostly solitary waves and it was used in many studies including Ramsden (1993), Wilson et al. (2009) and Fuchs (2013). Despite its wide application and use, this technique was criticized by Madsen et al. (2008) as solitary waves are typically associated with short wave length and high energy dissipation.

2. Landslide Generators - The concept implies the sudden drop of an external (generally) solid body into the water, producing a wave which travels in the opposite directions; this technique is particularly suitable to reproduce impulse waves. A landslide generator can be performed either manually by dropping a body inside the water (Thusyanthan \& Madabhushi 2008) or with more sophisticated mechanism such as a pneumatic landslide generator (Fritz 2002).

3. Dam-Break - This technique is based on the solution proposed by Ritter in 1892, with three fundamental hypothesis: (i) semi-infinite reservoir, (ii) ideal fluid, and (iii) horizontal frictionless bottom. The wave is obtained through the sudden removal of a gate and the propagation is described using a parabolic shape. A non-exhaustive list of studies that used such technique include Cross (1967), Yeh (1989), Chanson (2006), Arnason et al. (2009) and Nistor et al. (2009).

4. Vertical Release - This techniques implies the vertical drop of a certain water volume from a higher elevation into the channel. Similarly to the dam-break technique, a sudden difference in head is created such that water is further released through various mechanisms. The released volume can either be stored in an upper tank (Chanson et al. 2002, Meile 2007) or drawn upward mechanically and then released suddenly or using a control mechanism (Rossetto et al. 2011). 


\section{EXPERIMENTAL SET UP}

For the present study, the tsunami-like wave formation was achieved through a vertical release technique. The facility, previously used by Meile (2007), was adapted to produce waves with larger amplitudes and wavelengths. The generation mechanism is based on the sudden release of a known volume of water from an upper basin into a lower tank and then into the propagation channel. The experimental set-up is schematically presented in Figure 1 and an isometric view of the numerical model and a picture of the channel are shown in Figure 2.

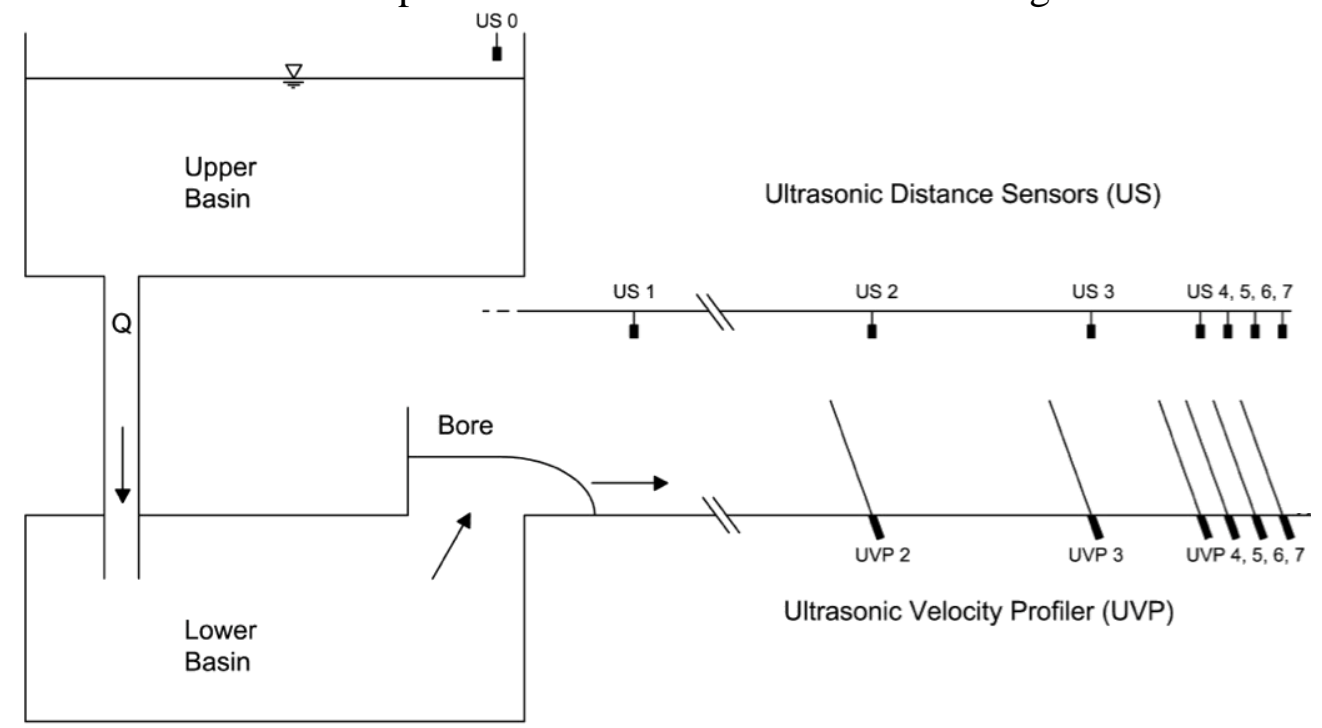

Figure 1. Conceptual representation of the Experimental set-up

A combination of three identical pipes with an internal diameter of $0.308 \mathrm{~m}$ was used to produce waves with different heights, velocities and wavelengths. In order to ensure the full development of the bore, the propagation of the wave took place in a horizontal smooth channel with a width of $1.4 \mathrm{~m}$ and a length of $14 \mathrm{~m}$. The transparent side walls had a height of $0.7 \mathrm{~m}$. A drainage pipe was installed under the wooden floor to guarantee the dry condition of the main channel.
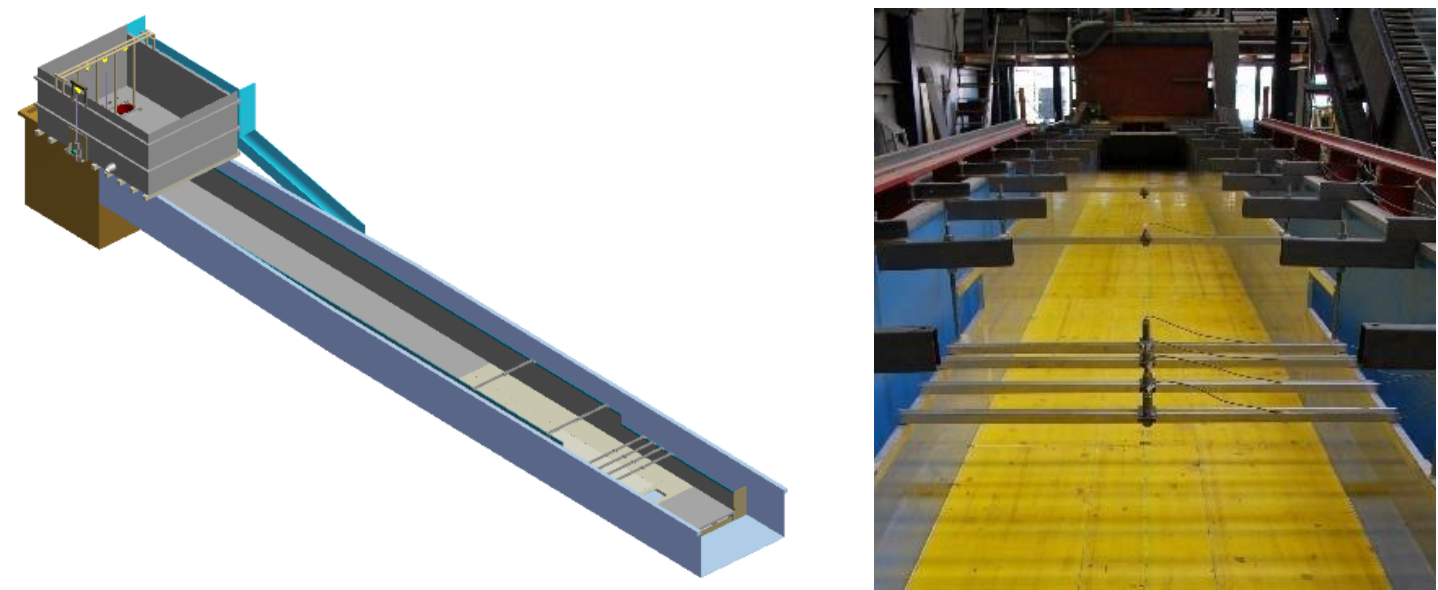

Figure 2. Isometric view of the numerical model (left); propagation channel (right) 
The sudden release was obtained through a clutch and pulleys system with inextensible ropes. The opening of the releasing mechanism was sufficiently fast to assure the criteria proposed by Lauber and Hager (1998). The connection of the lower basin with the laboratory pump system allowed the introduction of a discharge to simulate bores over wet bed. The maximum bore height was $0.3 \mathrm{~m}$, corresponding to a prototype height of $9 \mathrm{~m}$, if a 1:30 Froude scaling ratio was assumed. The timehistory of the bore height and its velocity along the channel were recorded using Ultrasonic Distance Sensors (US), Baumer UNAM 30I6103, sampled at a frequency of $1 \mathrm{kHz}$; a low-pass filter was used to post-process the signal. High-speed digital cameras and GoPro cameras installed at both the front and the lateral channel sides were used to capture the key spatial and temporal features of the wave.

\section{VISUAL OBSERVATIONS}

Both dry bed surges and wet turbulent bores were produced with identical releasing parameters (full tank and 3 pipes simultaneously open). A substantial difference, particularly in the bore front behavior was observed. The dry bed surge (Fig. 3, left) showed a sudden rise of the water level with a relatively thin edge, whereas the wet bed bore (Fig. 3, right) had a fully turbulent front characterized by strong aeration and a steeper bore front slope. For both configurations secondary waves and additional turbulence were observed on top of the propagating bore.
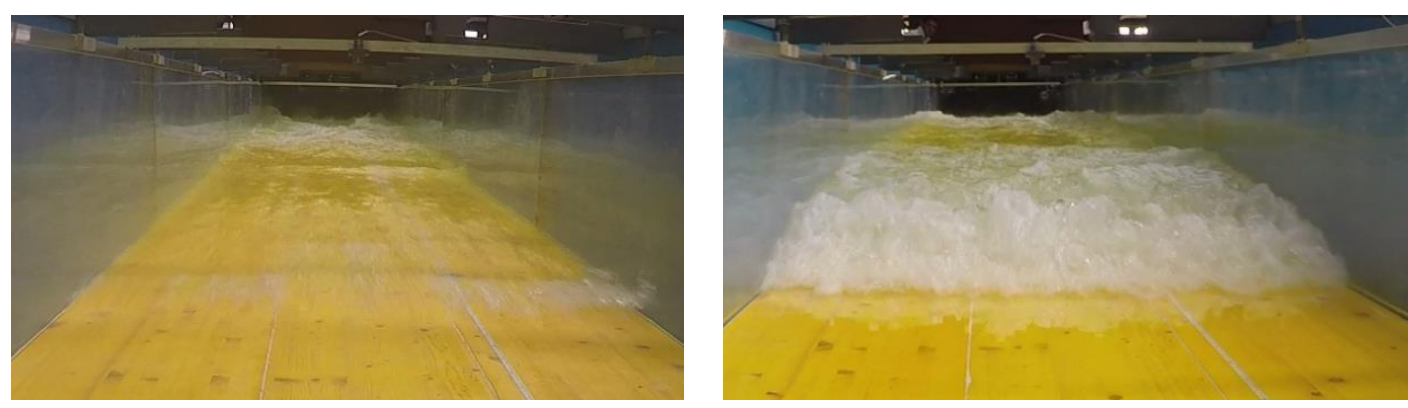

Figure 3. Dry bed surge (left); Wet bed bore, $h_{0}=5 \mathrm{~cm}$ (right)

\section{RESULTS}

The time history of the bore/surge profile was investigated using 7 US sensors dislocated along the channel at $x=2,10.1,12.1,13.1,13.35,13.6$ and 13.85 $\mathrm{m}$ from the channel inlet. The US sensors allowed to obtain an evolution over time of the wave, presented in Figure 4. Results showed that at US 7 quasi-uniform conditions of the wave were reached, implying that the wave was fully developed. The produced waves also had a good repeatability and uniformity in the lateral direction (not shown).

According to Chanson (2005) tsunamis and impulse waves can be treated using the dam break wave solution. The latter was published by Ritter (1892) and it represents a solution of the 1-D St-Venant equations, characterizing the propagating wave in terms of time $(t)$ and space $(x)$. 


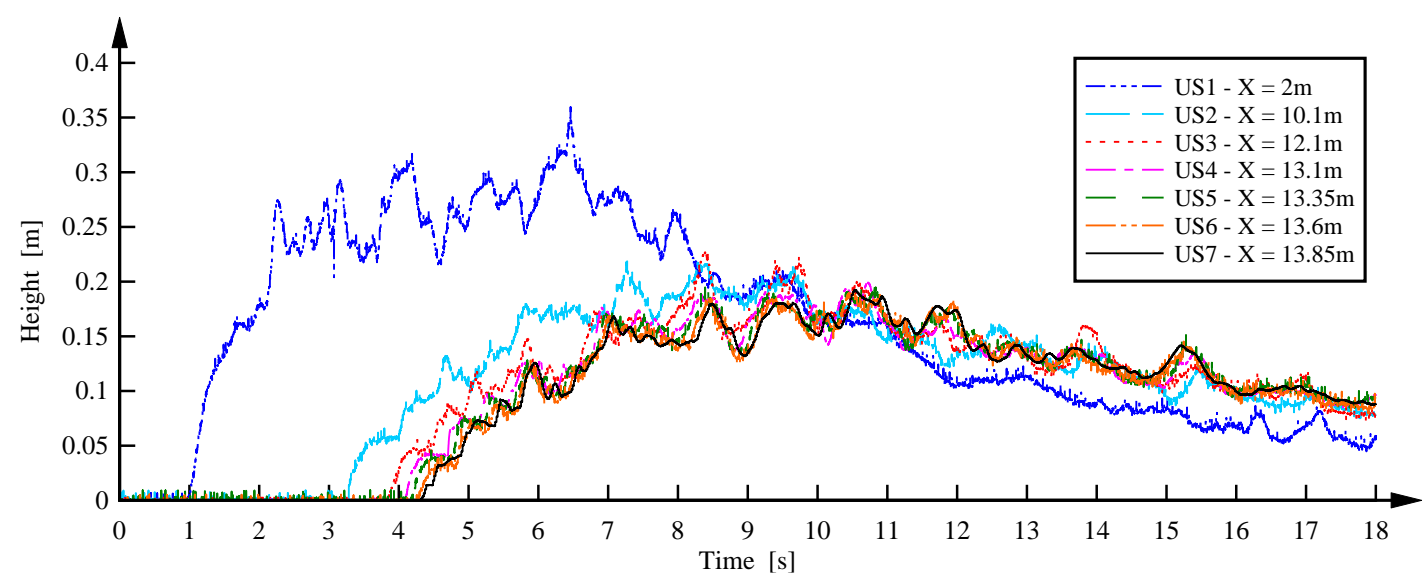

Figure 4. Evolution of the dry bed surge over time

The resulting expression is presented in Eq. 1 and it identifies a propagating wave with parabolic shape and constant height at $x=0$.

$\frac{d}{d_{0}}=\frac{1}{9} \cdot\left(2-\frac{x}{t \cdot \sqrt{g \cdot d_{0}}}\right)^{2}$

where $d$ is the wave height, $d_{0}$ is the initial reservoir height, $t$ is the time, $x$ is the streamwise coordinate and $g$ is the gravity constant $\left(g=9.81 \mathrm{~m} / \mathrm{s}^{2}\right)$. The experimental results obtained for several waves with identical characteristic are compared with Eq.1 in Figure 5; the latter represents the longitudinal profile of the propagating wave when the tip reached a height of $1 \mathrm{~cm}$ at the location of the US $7(x=13.85 \mathrm{~m})$. The best agreement with Ritter's solution was found for an initial height $d_{0}=0.7 \mathrm{~m}$. Such values are consistent with both visual observations of water level at channel inlet and geometrical limits due to channel lateral walls' height.

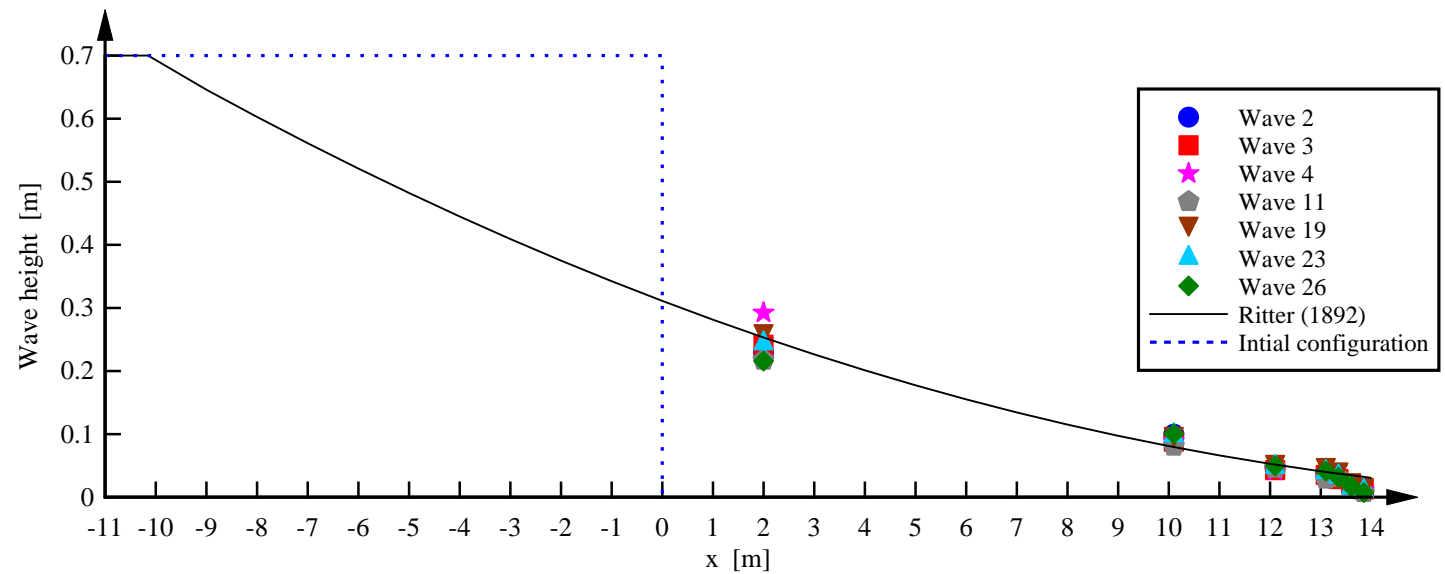

Figure 5. Comparison of the dry bed surge with the theory of Ritter (1892)

The analytical solution proposed by Whitham (1955) added friction to the propagating channel. He stated that in the dam break wave on horizontal bed with bottom friction two main parts can be distinguished: (1) a main body region and (2) a wave tip/edge region. In the main body region, the Ritter theory could be applied and the water behaved like an ideal fluid, whereas the wave tip region was dominated by 
friction with negligible inertia terms, resulting into a rounded shape with lower velocities. Whitham developed an analytical solution based upon the Pohlhausen technique and the integral treatment of the boundary layer (Chanson 2006). This solution made the assumption that in the wave tip/edge region the velocity distribution was constant. The resulting equation is presented in Eq.2.

$\frac{x-x_{s}}{d_{0}}=-\frac{f}{8} \cdot \frac{U^{2}}{g \cdot d_{0}} \cdot\left(\frac{g}{\partial U / \partial t}\right)^{2} \cdot\left[\ln \left(1+\frac{8}{f} \cdot \frac{d / d_{0}}{U^{2} / g \cdot d_{0}} \cdot \frac{\partial U / \partial t}{g}\right)-\frac{8}{f} \cdot \frac{d / d_{0}}{U^{2} / g \cdot d_{0}} \cdot \frac{\partial U / \partial t}{g}\right]$

where $\left(x-x_{s}\right)$ is the tip length, $d_{0}$ is the initial reservoir height $\left(d_{0}=0.7 \mathrm{~m}\right), f$ is the friction factor (assumed herein as $f=0.01$ ), $U$ is the tip/edge velocity $(U=3.56 \mathrm{~m} / \mathrm{s}$ ) while $\partial U / \partial t$ is the deceleration of the wave $\left(\partial U / \partial t=-0.1 \mathrm{~m} / \mathrm{s}^{2}\right)$. The velocity of the front, $U$, was derived from recordings of the US sensors. The experimental results are presented in Figure 4 together with the Ritter solution (Eq.1) and the Whitham solution (Eq.2): good agreement between the experimental points and the above mentioned equation was observed.

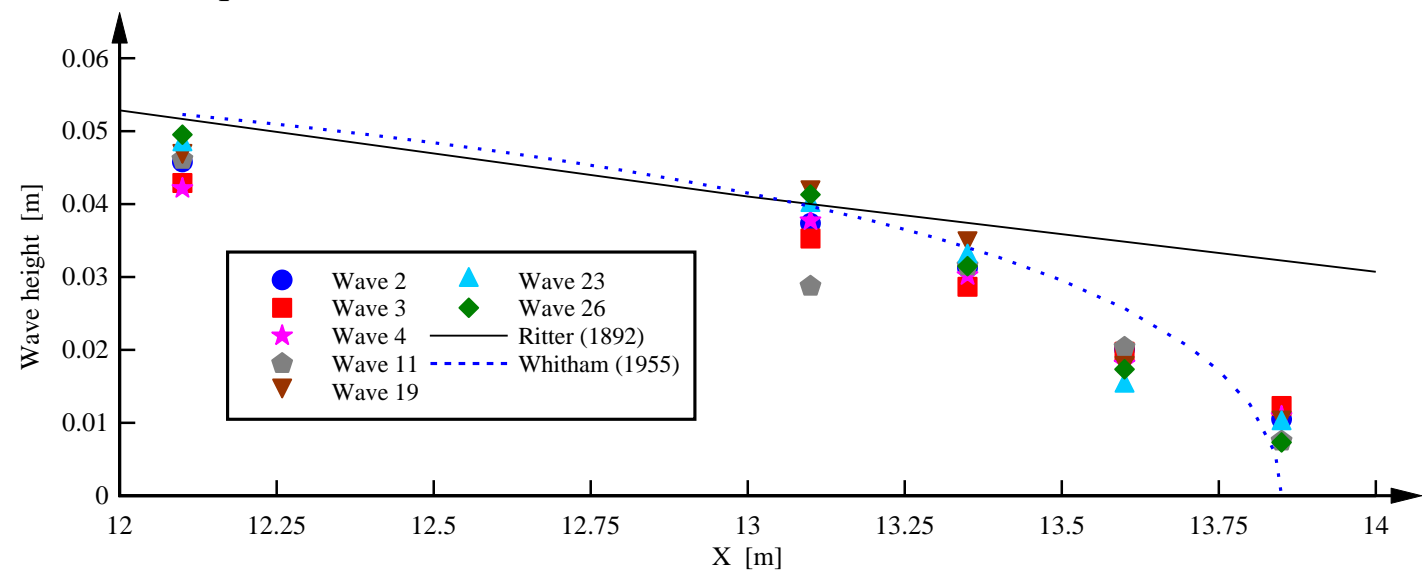

Figure 6. Comparison of the experimental points of the tip front with the theory of Ritter (1892) and Whitham (1955)

\section{EFFECTS OF THE WET VS. DRY BED CONDITION}

Both dry bed surges and wet bed bore were used in the experimental facility and their difference in terms of the behaviour of the propagation bore and surge was addressed in Section 4. The time-history of the water levels obtained for both the dry bed surge (continuous) and the wet bed bore (dotted) are presented in Figure 7. Differences can be observed especially in the first part of the profile while the profiles become similar after roughly $t=10 \mathrm{~s}$.

Similarities with the profiles previously obtained by Ramsden (1993) for waves with similar propagating velocity are evident. For the wet bore a turbulent aerated front was observed, whereas for the surge a sudden rise of the water level was identified (Fig. 3). Furthermore the profiles obtained from the US sensor showed a steeper front in the case of the wet bed bore. Lastly, the time gap between the arrival of the bore and of the surge indicated that dry bed surges were characterised 
by higher velocities: this last finding is consistent with literature and previous studies.

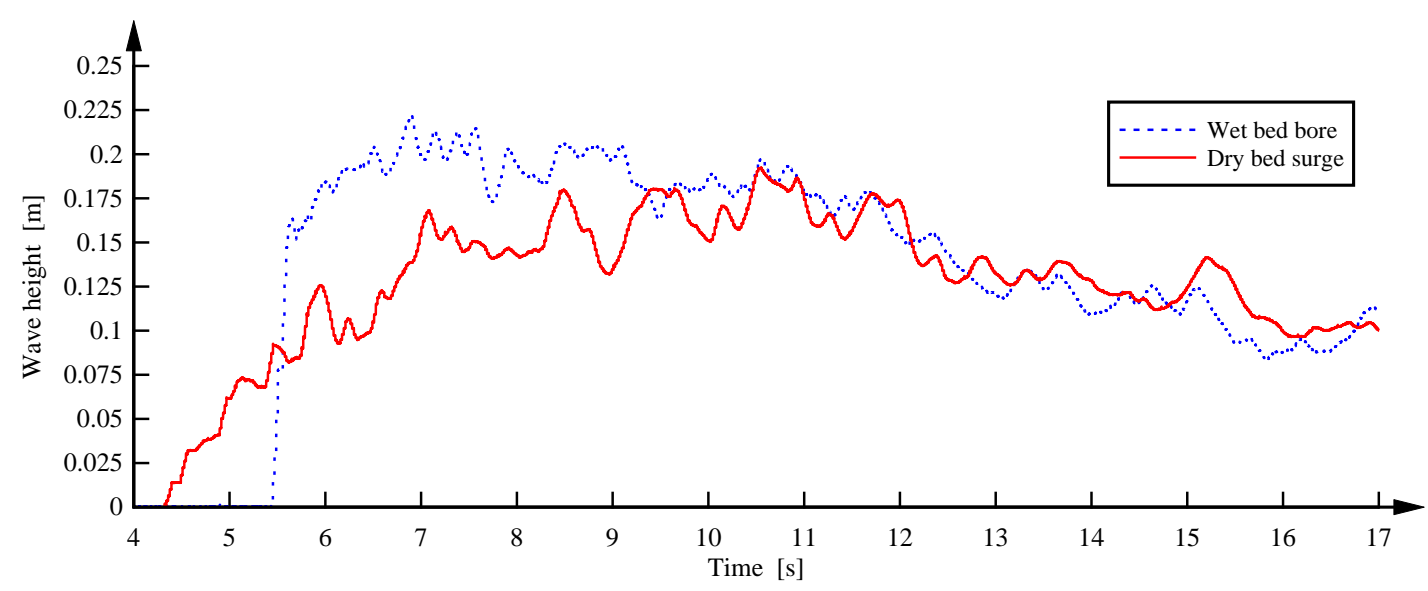

Figure 7. Time evolution of dry bed surge and wet bed bore (US 7)

\section{CONCLUSIONS}

This paper focused on the generation of waves and proposed a particular generation technique based on the vertical release of a determined volume of water from an upper reservoir through pipes into a lower reservoir which discharges into a straight channel. The latter was a modification of an already existing experimental facility used to obtain higher and faster waves that represented dam-breaks, tsunamis and impulse waves. The experimental work showed that dry bed surges propagating on a horizontal smooth channel had similar behavior with the theoretical solution proposed by Ritter (1892) for ideal fluids with a semi-infinite reservoir. In the wave tip/edge region a good agreement was also found with the shape derived from the Whitham (1955) solution. These finding confirmed that waves produced with this vertical release technique were similar to those produced using a "classical" dambreak generation set-up.

Finally, this paper also provided some qualitative differences between dry bed surges and wet bed bores. Main differences were observed in the front bore/surge shape: wet bed bore was found to be highly turbulent and aerated. The bore was also faster compared to the dry bed surge. Nevertheless, these results remain qualitative and more specific investigations are required to quantify these differences. Further work is planned in the context of this ongoing research project investigating the effect of structural porosity on the loading induced by extreme hydrodynamic events. The experimental program is expected to assist coastal and structural engineers in validating and improving the current design guidelines/standards for tsunami loading on infrastructure.

\section{REFERENCES}

Arnason, H., Petroff, C., and Yeh, H. (2009). Tsunami bore impingement onto a vertical column. Journal of Disaster Research, 4(6):391-403. 
Chanson, H. (2006). Tsunami surges on dry coastal plains: Application of dam break wave equations, Coastal Engineering Journal, 48(4):355-370.

Chanson, H., Aoki, S., and Maruyama, M. (2002). Unsteady air bubble entrainment and detrainment at a plunging breaker: dominant time scales and similarity of water level variations. Coastal Engineering, 46(2):139-157.

Chock, G., Carden, L., Robertson, I., Olsen, M., \& Yu, G. (2013). Tohoku tsunami-induced building failure analysis with implications for US tsunami and seismic design codes. Earthquake Spectra, 29(S1): S99-S126.

Cross, R. (1967). Tsunami surge forces. Journal of the Waterways and Harbours Division, 93(4): 201-231.

Fritz, H. (2002). Initial phase of landslide generated impulse waves. PhD Thesis. ETH/VAW, Zürich, 254 pages.

Fuchs, H. (2013). Solitary impulse wave run-up and overland flow. PhD Thesis. ETH/VAW, Zürich, 170 pages.

Lauber, G. and Hager,W. (1998). Experiments to dam-break wave: Horizontal channel. Journal of Hydraulic Research, 36(3):291-307.

Madsen, P., Fuhrman, D., and Schäffer, H. (2008). On the solitary wave paradigm for tsunamis. Journal of Geophysical Research: Oceans (1978-2012), 113(C12).

Meile, T. (2007). Influence of macro-roughness of walls on steady and unsteady flow in a channel. PhD Thesis No. 3952. and Communication 36 of Laboratory of Hydraulic Constructions, LCH/EPFL, Lausanne, (Ed. A. Schleiss).

Nistor, I., Palermo, D., Nouri, Y., Murty, T., and Saatcioglu,M. (2009). Tsunamiinduced forces on structures. Handbook of Coastal and Ocean Engineering. Singapore: World Scientific: 261-286.

Ramsden, J. (1993). Tsunami-forces on a vertical wall caused by long waves, bores and surges on a dry bed. California Institute of Technology, Pasadena, California, 218 pages.

Ritter, A. (1892). Die fortpflanzung de wasserwellen. Zeitschrift Verein Deutscher Ingenieure, 36(33):947-954.

Rossetto, T., Allsop,W., Charvet, I., and Robinson, D. (2011). Physical modelling of tsunami using a new pneumatic wave generator. Coastal Engineering, 58(6):517-527.

Thusyanthan, N. and Madabhushi, S. (2008). Tsunami wave loading on coastal houses: a model approach. Proceedings of the ICE-Civil Engineering, 161(2):77-86.

Whitham, G. (1955). The effects of hydraulic resistance in the dam-break problem. Proceedings of the Royal Society of London. Series A. Mathematical and Physical Sciences, 227(1170):399-407.

Wilson, J., Gupta, R., Van de Lindt, J., Clauson, M., and Garcia, R. (2009). Behavior of a onesixth scale wood-framed residential structure under wave loading. Journal of Performance of Constructed Facilities, 23(5):336-345.

Yeh, H., Ghazali, A., and Marton, I. (1989). Experimental study of bore run-up. Journal of fluid Mechanics, 206:563-578. 